\title{
Erratum to: Targeting CGRP: A New Era for Migraine Treatment
}

\author{
Stephanie Wrobel Goldberg ${ }^{1} \cdot$ Stephen David Silberstein $^{1}$
}

Published online: 11 April 2016

(c) Springer International Publishing Switzerland 2016

\section{Erratum to: CNS Drugs (2015) 29:443-452 DOI 10.1007/s40263-015-0253-Z}

Errors have subsequently been identified in the original publication, and the following corrections should be noted:

Page 447, column 1, paragraph 4, lines 6-13: The following two sentences, which previously read:

Four fully humanized mAbs are in different stages of phase I and II clinical trial investigation for the treatment of migraine. Three are targeting the CGRP ligand: LY2951742 (developed by Eli Lilly and Co.); ALD-403 (developed by Alder Biopharmaceuticals); and TEV-48125
(LBR-101) (developed by Teva Pharmaceuticals); and one against its receptor, AMG 334 (in development by Amgen).

Should read:

Four mAbs are in different stages of phase I and II clinical trial investigation for the treatment of migraine. Three fully humanised mAbs target the CGRP ligand: LY2951742 (developed by Eli Lilly and Co.); ALD-403 (developed by Alder Biopharmaceuticals); and TEV-48125 (LBR-101) (developed by Teva Pharmaceuticals); and one fully human $\mathrm{mAb}$ targets the CGRP receptor, AMG 334 (in development by Amgen).

The online version of the original article can be found under doi:10.1007/s40263-015-0253-z.

Stephanie Wrobel Goldberg

stephwg@gmail.com

Stephen David Silberstein

stephen.silberstein@jefferson.edu

1 Department of Neurology, Jefferson Headache Center,

Thomas Jefferson University, 900 Walnut Street, Suite 200,

Philadelphia, PA 19107, USA 